\title{
Key stakeholders' views on the potential implementation of pharmacist prescribing: a qualitative investigation.
}

JEBARA, T., CUNNINGHAM, S., MACLURE, K., PALLIVALAPILA, A., AWAISU, A., AL HAIL, M., STEWART, D. 
3 Tesnime Jebara ${ }^{1}$, Scott Cunningham ${ }^{1}$, Katie MacLure ${ }^{1}$, Abdulrouf Pallivalapila ${ }^{2}$, Ahmed Awaisu ${ }^{3}$, Moza Al

4 Hail $^{2}$, Derek Stewart ${ }^{3}$

$5{ }^{1}$ School of Pharmacy and Life Sciences, Robert Gordon University, Sir Ian Wood Building, Garthdee Road,

6 Aberdeen, United Kingdom, AB10 7GJ

$7 \quad{ }^{2}$ Pharmacy Department, Women's Wellness and Research Center, Hamad Medical Corporation, Doha, Qatar, PO

8 Box 3050

$9 \quad{ }^{3}$ College of Pharmacy, Qatar University, Doha, Qatar, P.O. Box 2713

10

11 Correspondence to:

12 Professor Derek Stewart

13 College of Pharmacy

14 Qatar University Health

15 Qatar University

16 P.O. Box 2713

17 Doha, Qatar

18 Email: d.stewart@qu.edu.qa

19

20 Declarations of interest: None. 


\section{Abstract}

22 Background: An accumulation of international evidence demonstrates that pharmacist prescribing is effective, 23 safe and well-accepted. While there is potential for such development in the Middle East, the majority of 24 published studies are largely reported from Western countries and the perspectives of individuals in strategic 25 positions of policy and practice in the Middle East were unknown.

26 Objective: To explore the views of key stakeholders in Qatar regarding the potential development and implementation of pharmacist prescribing.

28 Methods: Qualitative, face-to-face semi-structured interviews were conducted with stakeholders in strategic 29 positions of policy influence (i.e. medical, pharmacy and nursing department directors, health-related 30 academics, patient safety and quality directors, professional regulators). Stakeholders were recruited via 31 purposive and snowball sampling. The interview schedule was constructed from an extensive literature review 32 and grounded in the Consolidated Framework for Implementation Research (CFIR) to ensure comprehensive 33 exploration of potential facilitators and barriers. Interviews were conducted from April to August 2017, digitally 34 recorded, transcribed, and independently analysed by two researchers using CFIR as a coding framework.

35 Results: Thirty-seven interviews were conducted with directors of medicine $(n=5)$, pharmacy $(n=6)$ and nursing $36(n=5)$, healthcare policy developers $(n=6)$, healthcare academics $(n=9)$, and patient safety advocates $(n=6)$.

37 Interviewees were aware of pharmacist prescribing models internationally and generally supported development 38 and implementation in Qatar due to perceived benefits of improved patient care, professional development and 39 enhanced team working. While there were more facilitators than barriers, it was clear that there was a 40 requirement to systematically plan the development and implementation of pharmacist prescribing, with 41 reference to all five CFIR domains. The need for further training, demonstration of pharmacists' prescribing 42 competence, and extensive engagement of stakeholders were considered crucial.

43 Conclusion: There is potential for pharmacist prescribing to be developed and implemented in Qatar. Further 44 research is warranted to define the models of prescribing suitable for Qatar, and to highlight issues of education, 45 training and accreditation.

46 Keywords: prescribing, clinical pharmacy, implementation, pharmacist, Qatar 
48 Prescribing by pharmacists has been implemented in several countries including the United Kingdom (UK),

49 United States of America (USA), Canada, and New Zealand. ${ }^{1}$ While the specific prescribing legislation varies

50 from country to country, the three main models are independent prescribing, supplementary prescribing, and

51 collaborative prescribing. ${ }^{2}$ According to the UK Department of Health (2006), the aims of non-medical

52 prescribing (i.e. prescribing by suitably qualified health professionals other than doctors and dentists) in the UK

53 are to: improve patient care without compromising patient safety, make it easier for patients to get the medicines

54 they need, increase patient's choice in accessing medicines, make better use of the skills of healthcare

55 professionals, and contribute to the introduction of more flexible team working across the National Health

56 Service. $^{3}$

57 There is increasing evidence of the effectiveness and safety of pharmacist prescribing derived from systematic

58 reviews and meta-analyses. ${ }^{4}$ A Cochrane review of 46 studies (37,337 participants) of prescribing by

59 pharmacists (20 studies) and nurses (26 studies) compared to medical prescribing was conducted. ${ }^{5}$ It concluded

60 that pharmacist and nurse prescribers, practising with varying but high levels of prescribing autonomy, in a

61 range of settings, were as effective as usual care by medical prescribers for a range of acute and chronic conditions. ${ }^{5}$ A more recent systematic review of pharmacist prescribing compared to medical prescribing in the hospital setting (15 studies) reported equivalent or improved outcomes for blood pressure, cholesterol, glucose, anticoagulation, satisfaction, and medication adherence. ${ }^{6}$ Stakeholders' views and experiences of pharmacist prescribing implementation have also been consistently positive, as reported in a systematic review of 65 studies. ${ }^{7}$ Twenty-nine studies were conducted prior to implementation, 35 post-implementation, and one was conducted both pre- and post-implementation of pharmacist prescribing. The overwhelming findings of this review were encouraging, particularly in relation to increased access to healthcare services, perceptions of improved patients' outcomes, better utilisation of pharmacists' skills and knowledge, improved job satisfaction, and reduced physicians' workload. Concerns were largely identified pre-implementation and were around organisational issues and perceived lack of pharmacists' diagnosis skills. ${ }^{7}$ One limitation of the studies included in this review was that all were conducted in the Western world; hence, the findings may not be generalisable or transferable to other regions with differing healthcare systems, ethnicity, culture, and work practices.

74 Furthermore, none of the studies applied implementation theory to the research design, data collection or analysis hence may not have comprehensively captured all relevant factors. There was also a paucity of qualitative studies hence a lack of depth and richness of findings. ${ }^{7}$

The need to consider theory in developing and implementing interventions such as pharmacist prescribing is articulated in the UK Medical Research Council (MRC) Framework for Developing and Evaluating Complex Interventions. ${ }^{8}$ According to this framework, a new model of prescribing would be considered a 'complex intervention' given the number of groups and organisational levels affected, the degree of behaviour change required and the number and variability of outcomes. Embedding implementation theory throughout the development and implementation stages is likely to lead to more effective, efficient, and sustained change compared to a more pragmatic approach. ${ }^{9}$ The Consolidated Framework for Implementation Research (CFIR) was developed in an attempt to simplify the selection of the most appropriate implementation theory from the multitude of theories, many of which have different terminologies, are often overlapping, and lack one or more 
key elements. CFIR is a synthesis of 18 published models, theories, and frameworks that facilitate translation of research findings into practice. ${ }^{10,11}$ Figure 1 summarises the five CFIR domains which can positively or negatively influence implementation: characteristics of innovation being implemented into a particular organisation, outer setting (economical, political, and social context within which an organisation resides), inner setting (structural, political, and cultural context through which implementation process will proceed), characteristics of individuals involved, and process of implementation. ${ }^{10,11}$ CFIR may, therefore, enable a more comprehensive consideration of key issues related to the development and implementation of pharmacist prescribing.

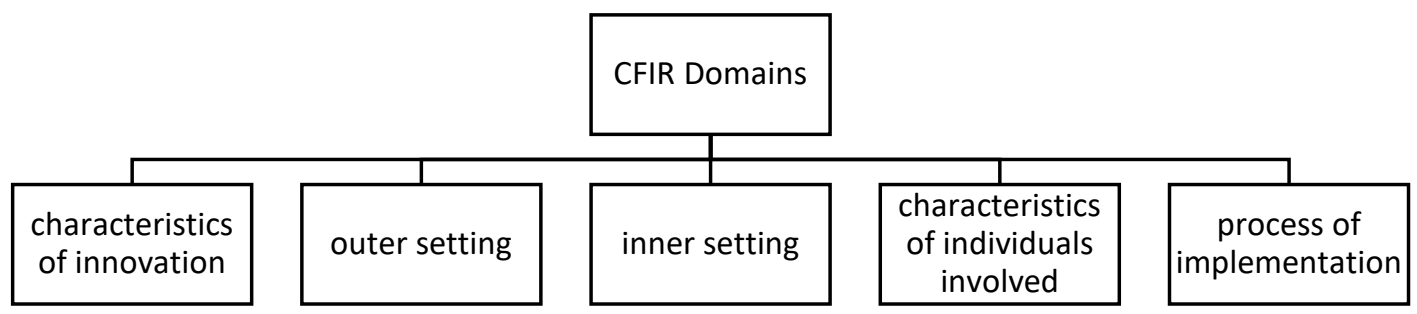

Figure 1: CFIR domains

The State of Qatar, a peninsula situated halfway along the western coast of the Arabian Gulf, has had the highest gross domestic product (GDP) per capita globally for the past 10 years. ${ }^{12}$ Over this period, Qatar has taken action to transform the healthcare system (Figure 2) in order to achieve better patient care outcomes for current and future generations, as outlined in its National Vision 2030 and National Health Strategy. One aim is to establish “a comprehensive world-class healthcare system”, with emphasis on shifting care from secondary and tertiary settings to primary care and better utilise the skilled and motivated workforce, including pharmacists. ${ }^{13-}$ ${ }^{16}$ There is, hence, the potential to embed pharmacist prescribing within healthcare settings in Qatar. This study aimed to explore the views of key stakeholders on the potential of developing and implementing pharmacist prescribing in Qatar.

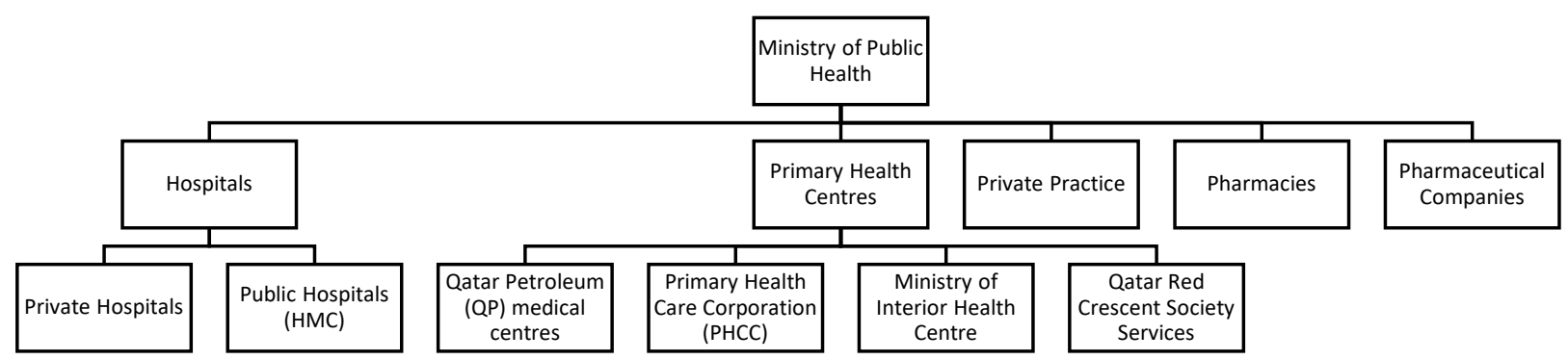


111 A qualitative approach was selected in an attempt to obtain in-depth perspectives key stakeholders. Semi-

112 structured interviews were chosen over focus groups for several reasons including the desire to obtain individual

113 rather than collective views and the logistical difficulties of scheduling focus groups with high profile

114 participants.

\section{$115 \quad$ Settings}

116 Data generation took place in Qatar, across all major organisations and institutions relating to the practice,

117 education, regulation and governance of pharmacists. These comprised of the Ministry of Public Health

118 (MoPH); primary, secondary, and tertiary healthcare settings; community pharmacies; and all healthcare

119 academic institutions providing medicine, nursing, pharmacy, and pharmacy technician education programmes

120 in Qatar.

\section{Inclusion and exclusion criteria}

122 The intention was to generate data representing all key stakeholder groups in Qatar, including experts in their 123 respective fields with policy influence relating to the development and implementation of models of care. The 124 groups targeted were individuals in key strategic positions of policy influence "(i.e. medical, pharmacy and 125 nursing department directors, health-related academics, patient safety and quality directors, professional 126 regulators). These stakeholders were recruited from: the Ministry of Public Health; the largest governmental

127 hospital group; the largest governmental and private primary healthcare settings; the different governmental and 128 private academic healthcare institutes; and the largest private community pharmacy chains.

\section{Sampling and sample size}

130 The sampling frame included all individuals meeting the inclusion and exclusion criteria. Names and contact 131 details were collated by the research team members based in Qatar, using their professional networks. Purposive 132 sampling, representing diversity of years of experience and country of professional training, was adopted. This 133 allowed identifying and approaching those individuals most likely to contribute to the achievement of the 134 research aim and provide valuable insight through multiple perspectives. In addition, snowball sampling was 135 also used to ensure that no key individuals had been omitted, by asking each interviewee to recommend others 136 that they thought important to include. Recruitment continued to the likely point of data saturation for each 137 stakeholder group (i.e. the point at which no new themes emerged). ${ }^{17}$

\section{Interview schedule development}

139 The semi-structured interview schedule was drawn from a comprehensive literature review, an umbrella review

140 of systematic reviews on non-medical prescribing and the systematic review of views and experiences

141 conducted by the research team. ${ }^{4,7}$ CFIR $^{10}$ was incorporated into the interview schedule to ensure 
143 The schedule was reviewed for credibility by members of the research team prior to piloting with five healthcare academic and practice-based stakeholders, who were subsequently excluded from the dataset. No changes were made based following the pilot interviews hence these were included as part of the dataset. An overview of the interview schedule questions and alignment to the research questions and CFIR are presented in Table 1.

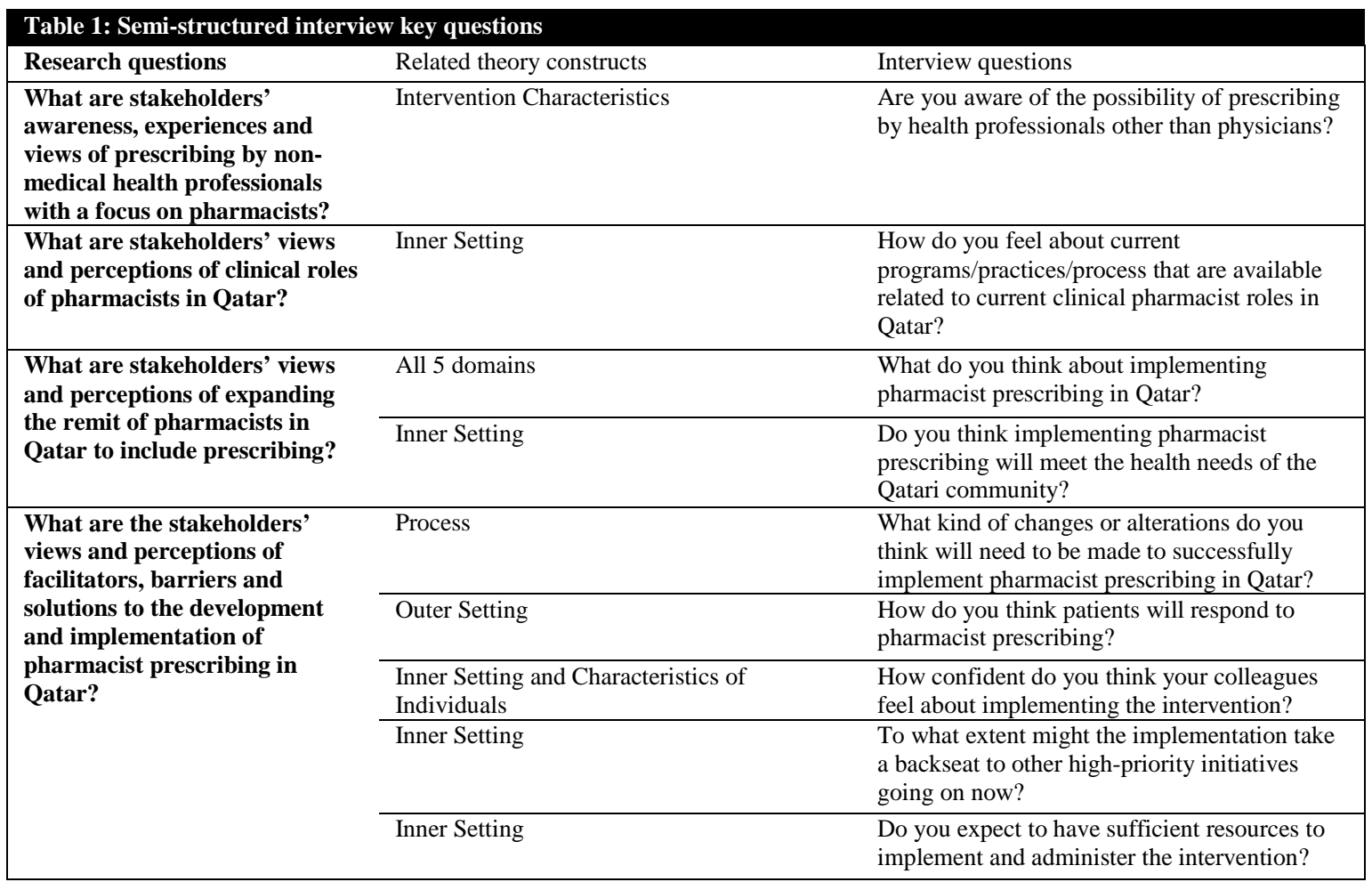

148 From April to August 2017, all potential stakeholders were invited via email to participate and provided with

149 detailed study information. If agreeing, a convenient location, date and time for interview was negotiated.

150 Interviews of approximately 45-60 minutes were conducted by a trained researcher with a background in

151 pharmacy. Probes, such as 'can you tell me more about that' and 'what did you mean when you said...' were

152 used throughout the interviews to obtain detailed responses and explanations. Interviews were digitally audio-

153 recorded and transcribed verbatim as soon as possible following completion of the interview. All interviewees

154 were offered the opportunity to review the transcripts to promote credibility and dependability. ${ }^{18}$

\section{Data analysis}

156 Thematic analysis was conducted according to the steps outlines by Howitt. ${ }^{19}$ On completion of transcribing, all 157 interviews were input into NVivo ${ }^{\circledR}$ software. Initial coding was as per CFIR constructs followed by

158 identification and definition of emerging themes under each construct. Each theme was then characterised as a

159 facilitator or a barrier to development and implementation. The analysis was independently conducted by two

160 researchers (TJ and one other), with any disagreements resolved through discussion. 
163 Ethical approval was received from Robert Gordon University (RGU) School of Pharmacy \& Life Sciences

164 Research Ethics Committee (Approval reference S64), Ministry of Public Health (MoPH) Ethics Committee,

165 Hamad Medical Corporation (HMC) Medical Research Committee (Approval reference MRC0449/2017), and

166 Qatar University (QU) Institutional Review Board (Approval reference QU-IRB 772-E/17). Written, informed 167 consent was obtained from all research participants before commencing the interviews.

\section{Results}

\section{Stakeholder recruitment}

170 Data saturation was deemed to have been achieved in each stakeholder group after 37 interviews had been

171 completed. Stakeholder groups and details of interviewees are presented in Table 2.

\begin{tabular}{|c|c|}
\hline Stakeholder category & Setting: Number of interviewees \\
\hline Academic leaders & $\begin{array}{ll}- & \text { Medicine: } 2 \\
\text { - } & \text { Pharmacy and Pharmacy technician: } 5 \\
\text { - } & \text { Nursing: } 2\end{array}$ \\
\hline Healthcare policy developers & $\begin{array}{ll}\text { - } & \text { Primary care/Community: } 1 \\
\text { - } & \text { Secondary care: } 1 \\
\text { - } & \text { Tertiary care: } 2 \\
\text { - } & \text { Corporate/Ministry: } 2\end{array}$ \\
\hline Medical practice leaders & $\begin{array}{ll}\text { - } & \text { Secondary care: } 2 \\
\text { - } & \text { Tertiary care: } 3\end{array}$ \\
\hline Pharmacy practice leaders & $\begin{array}{ll}\text { - } & \text { Primary care/Community: } 2 \\
\text { - } & \text { Secondary care: } 1 \\
\text { - } & \text { Tertiary care: } 2 \\
\text { - } & \text { Corporate/Ministry: } 1\end{array}$ \\
\hline Nursing practice leaders & $\begin{array}{ll}\text { - } & \text { Secondary care: } 1 \\
\text { - } & \text { Tertiary care: } 2 \\
\text { - } & \text { Corporate/Ministry: } 2\end{array}$ \\
\hline Patient safety advocates & $\begin{array}{ll}\text { - } & \text { Primary care/Community: } 1 \\
\text { - } & \text { Secondary care: } 1 \\
\text { - } & \text { Tertiary care: } 4\end{array}$ \\
\hline
\end{tabular}

\section{Themes}

173 The themes identified, mapped to CFIR domains and constructs, are summarised in Table 3. In general, there

174 were no marked differences in responses from interviewees across the professional groupings. 


\begin{tabular}{|c|c|c|c|}
\hline $\begin{array}{l}\text { CFIR } \\
\text { domain }\end{array}$ & CFIR constructs & Themes & Illustrative quotes \\
\hline \multirow{15}{*}{ 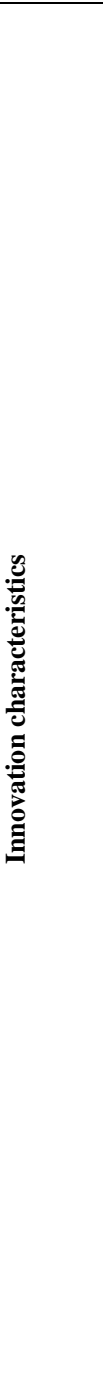 } & \multirow{5}{*}{ Innovation source } & $\begin{array}{l}\text { Many of the interviewees across all stakeholder groups were aware of the } \\
\text { concept of non-medical, and specifically pharmacist, prescribing. }\end{array}$ & $\begin{array}{l}\text { "Worldwide, there are different and many models of prescribing. So there is the North American model } \\
\text { which is usually in most cases more of a collaborative framework... In the UK they started a decade or } \\
\text { two ago to have independent prescribing models for both nurses and pharmacists... But even many other } \\
\text { countries have started to do that." }\end{array}$ \\
\hline & & Several were, however, less aware of non-medical prescribing practice. & "I am not sure actually. Where I come from in Germany or Switzerland that is not the case. In the United \\
\hline & & & States, I think it is the case but I don’t know to what extent.” \\
\hline & & $\begin{array}{l}\text { Interviewees highlighted that this was not currently within scope of } \\
\text { practice in Qatar. }\end{array}$ & $\begin{array}{l}\text { "They will advise the doctor that this is right or you need to modify... But not a direct dealing with } \\
\text { prescribing." } \\
\text { Patient Safety Advocate } 2\end{array}$ \\
\hline & & $\begin{array}{l}\text { There was recognition of the new role within anticoagulation which } \\
\text { required physicians' co-signatures. }\end{array}$ & $\begin{array}{l}\text { "I only know at Heart Hospital, they have anticoagulation clinic where the pharmacists are involved... I } \\
\text { think they are recommending the doses and the doctors will agree." } \\
\text { Academic Leader } 4\end{array}$ \\
\hline & $\begin{array}{l}\text { Evidence strength and } \\
\text { quality }\end{array}$ & $\begin{array}{l}\text { Most considered the evidence around this initiative of sufficient quantity } \\
\text { and strength to support developments in other countries. }\end{array}$ & $\begin{array}{l}\text { "Pharmacist prescribing privileges in the UK... has been established since long time and there is also } \\
\text { enough data to show the effectiveness and the efficiency of such initiative." Academic Leader } 3\end{array}$ \\
\hline & \multirow{7}{*}{$\begin{array}{l}\text { Relative } \\
\text { advantage }\end{array}$} & $\begin{array}{l}\text { There were particular advantages to the pharmacists themselves by } \\
\text { increasing their job satisfaction and confidence. }\end{array}$ & $\begin{array}{l}\text { "It will increase their self-confidence, they will feel that they are able to contribute more to society, they } \\
\text { will feel that they are really a valued member of the healthcare team." Academic Leader } 1\end{array}$ \\
\hline & & $\begin{array}{l}\text { There were benefits for physicians, with reduced time spent on } \\
\text { prescribing. }\end{array}$ & "This will also reduce the pressure that we put on the physicians." \\
\hline & & $\begin{array}{l}\text { It could lead to more timely access to care and improved patient } \\
\text { satisfaction. }\end{array}$ & $\begin{array}{l}\text { "That would also enhance the patient experience itself in terms of waiting time, quick access to } \\
\text { healthcare professionals." } \\
\text { Healthcare Policy Leader } 2\end{array}$ \\
\hline & & $\begin{array}{l}\text { Pharmacist prescribers could be more effective and safer than physicians } \\
\text { given their education and training on medication. }\end{array}$ & $\begin{array}{l}\text { "When I look at the data we currently have, there is definitely room for improvement... I think having } \\
\text { people who are specifically trained and experienced in that area has got to be better." } \\
\text { Healthcare Policy Leader } 5\end{array}$ \\
\hline & & This has also the potential for reducing the cost of healthcare. & $\begin{array}{l}\text { "When you make the physicians’ time available for more complicated cases, this may be associated with } \\
\text { cost reduction." } \\
\text { Academic Leader } 3\end{array}$ \\
\hline & & $\begin{array}{l}\text { It could also impact the roles and responsibilities of pharmacy } \\
\text { technicians. }\end{array}$ & $\begin{array}{l}\text { "I know pharmacy technicians will obviously have more responsibilities because the pharmacists will } \\
\text { have to spend time with the patients." } \\
\text { Academic Leader } 4\end{array}$ \\
\hline & & $\begin{array}{l}\text { The image of the profession may also improve resulting in increased } \\
\text { applications to study pharmacy in Qatar. }\end{array}$ & $\begin{array}{l}\text { "Having privileges for pharmacists to prescribe medications will really help in improving the pharmacy } \\
\text { picture in the community... It will help in recruiting more national pharmacists." } \\
\text { Academic Leader } 3\end{array}$ \\
\hline & Trialability & $\begin{array}{l}\text { Another key theme was the need to start slowly by piloting in defined } \\
\text { areas prior to implementing on a wider scale. }\end{array}$ & $\begin{array}{l}\text { "I would strongly advocate that we start small... If it demonstrates and achieves benefits, then that is the } \\
\text { reason to try a bit more probably." } \\
\text { Healthcare Policy Leader } 5\end{array}$ \\
\hline & Complexity & $\begin{array}{l}\text { The potential complexity of pharmacist prescribing particularly in } \\
\text { relation to diagnostic skills was also raised. }\end{array}$ & $\begin{array}{l}\text { "If it is left to the pharmacist to make a clinical diagnosis and write a prescription, that to me, is beyond } \\
\text { the scope, I think." } \\
\text { Patient Safety Advocate } 5\end{array}$ \\
\hline
\end{tabular}




\begin{tabular}{|c|c|c|c|}
\hline & & Embedding sufficient quality assurance was also highlighted. & $\begin{array}{c}\text { "The challenge is just to secure the quality that is needed to make this a reality." } \\
\text { Medical Practice Leader } 1\end{array}$ \\
\hline & & $\begin{array}{l}\text { There was also a concern over conflict with physicians, particularly if } \\
\text { independently prescribing. }\end{array}$ & $\begin{array}{l}\text { "The disadvantage would be the conflict... because if you create some kind of independency among } \\
\text { clinical pharmacist, he might work away from the physicians' direction.” } \quad \text { Medical Practice Leader } 3\end{array}$ \\
\hline & & $\begin{array}{l}\text { Some interviewees highlighted that the current legislative framework } \\
\text { could be a barrier to be overcome. }\end{array}$ & $\begin{array}{l}\text { "You have to change the law which is not easy... How you are going to handle this legal framework? } \\
\text { How are you going to make it legal for the pharmacists?" }\end{array}$ \\
\hline & & Another concern was the possibility of overburdening pharmacists. & $\begin{array}{l}\text { "The other disadvantage is... overburdening the pharmacists with prescribing duties as well as clinical } \\
\text { duties on the ward." }\end{array}$ \\
\hline \multirow{2}{*}{ 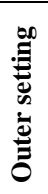 } & Needs and resources & $\begin{array}{l}\text { Public perceptions of pharmacists, their training, and abilities may hinder } \\
\text { implementation. }\end{array}$ & $\begin{array}{l}\text { "Many patients, especially in the Arab region, will tell you "Ah, pharmacist? He just dispense } \\
\text { medication. I would trust the physician more”." } \\
\text { Academic Leader } 2\end{array}$ \\
\hline & Cosmopolitanism & $\begin{array}{l}\text { The fact that pharmacist prescribing had been successfully implemented } \\
\text { in other countries could facilitate implementation in Qatar. }\end{array}$ & $\begin{array}{l}\text { "You have to connect them with other experience or to be affiliated with another organisation whom } \\
\text { they have the same program for example prescribing in Canada, USA, UK..." } \\
\text { Patient Safety Advocate } 1\end{array}$ \\
\hline \multirow{5}{*}{ 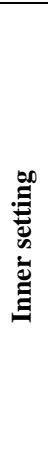 } & $\begin{array}{l}\text { Networks and } \\
\text { Communications }\end{array}$ & $\begin{array}{l}\text { Interviewees highlighted that health professionals working in hospitals } \\
\text { were more aware of pharmacists' clinical roles. }\end{array}$ & $\begin{array}{l}\text { "Talking about physicians and nurses because they are in a daily contact with the pharmacists, they are } \\
\text { aware of the pharmacist’s role especially when we say in the hospitals... But talking about maybe } \\
\text { community, I think no." } \\
\text { Academic Leader } 3\end{array}$ \\
\hline & Culture & $\begin{array}{l}\text { There were mixed views relating to organisational culture within Qatar in } \\
\text { relation to embracing change. }\end{array}$ & $\begin{array}{l}\text { "You will always get people who embrace the change very, very quickly and you always get people who } \\
\text { are really kind of slow to adopt the change." }\end{array}$ \\
\hline & \multirow[t]{2}{*}{ Implementation climate } & $\begin{array}{l}\text { Interviewees perceived several positive drivers } \\
\text { for change such as the lack of physicians. }\end{array}$ & $\begin{array}{l}\text { "With the increased costs of healthcare and shortage of healthcare providers including physicians of } \\
\text { course, there is a need to widen the scope of prescribing." }\end{array}$ \\
\hline & & $\begin{array}{l}\text { Another driver was the quality of pharmacy } \\
\text { education in Qatar. }\end{array}$ & $\begin{array}{l}\text { "I think you have probably got more chances of getting pharmacists prescribing than nurses. There is a } \\
\text { very strong academic programme for pharmacists in Qatar..." }\end{array}$ \\
\hline & $\begin{array}{l}\text { Readiness for } \\
\text { implementation }\end{array}$ & $\begin{array}{ll}\text { Leadership engagement } & \begin{array}{l}\text { There are currently discussions on extending } \\
\text { pharmacist roles. }\end{array}\end{array}$ & $\begin{array}{l}\text { "For my end, I have no objection to it and I am already pushing it ahead now with a fairly senior } \\
\text { consultant." }\end{array}$ \\
\hline \multirow{4}{*}{ 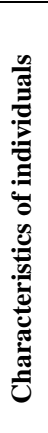 } & $\begin{array}{l}\text { Knowledge and beliefs } \\
\text { about the innovation }\end{array}$ & $\begin{array}{l}\text { Many highlighted how the knowledge base of pharmacists could facilitate } \\
\text { pharmacist prescribing. }\end{array}$ & $\begin{array}{l}\text { "I think pharmacists certainly from my contacts have a tremendous amount of knowledge. They need to } \\
\text { be supported in expanding their scope of practice." } \\
\text { Academic Leader } 9\end{array}$ \\
\hline & Self-efficacy & Many commented on pharmacists' self-efficacy to prescribe. & $\begin{array}{l}\text { "Pharmacists perceptions about their own roles and responsibility, maybe about their own self- } \\
\text { confidence, maybe they don’t feel ready.” }\end{array}$ \\
\hline & \multirow[b]{2}{*}{$\begin{array}{l}\text { Other personal } \\
\text { attributes }\end{array}$} & Others felt that pharmacists were competent enough to prescribe. & $\begin{array}{l}\text { "I don't think our pharmacists are less than these countries where these models occurred especially that } \\
\text { you always have these tests or requirements to get competence." } \\
\text { Healthcare Policy Leader } 2\end{array}$ \\
\hline & & $\begin{array}{l}\text { Interviewees highlighted need for experience in clinical practice prior to } \\
\text { undertaking prescribing. }\end{array}$ & $\begin{array}{l}\text { "I would say that they should definitely have at least five years of experience because I think those also } \\
\text { build your confidence and your skills and you can begin to see patterns in patients." } \\
\text { Academic Leader } 9\end{array}$ \\
\hline
\end{tabular}




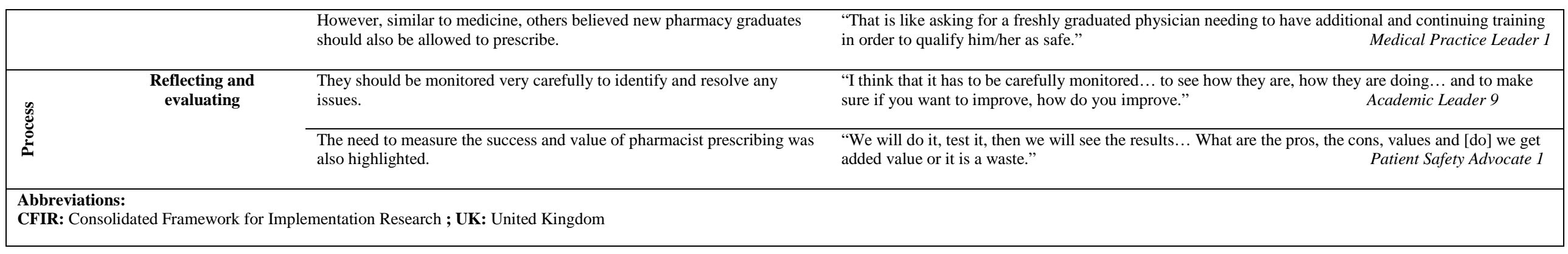


175 The more dominant themes in terms of the depth of discussion and the number of participants discussing each

176 were those around the preferred design, relative priority, available resources, and planning. Therefore, these are

177 described in more details below.

\section{$178 \quad$ CFIR domain 1: Innovation characteristics}

179

180

181

182

183

184

185

186

187

188

189

190

191

192

193

194

195

196

197

198

199

200

201

202

203

204

205

206

207

\section{Design quality and packaging}

(Defined in the framework as the perceived excellence in how the innovation is bundled, presented, and assembled)

On discussion of the preferred model of pharmacist prescribing and its implementation, there was an overwhelming view that it would be best to be more conservative, particularly in the initial stages, prior to proceeding to a more autonomous model. This was highlighted by all stakeholder groups.

"At the time being, I believe that [collaborative prescribing] will be the foundation for things that we have then after that we will focus on independent.”

Pharmacy Practice Leader 3

The importance of clearly identifying the need for pharmacist prescribing and targeting therapeutic areas and patient groups was emphasised.

"I think it is also important to see that there is a need for it. Not just do it in all the areas, no."

Academic Leader 1

However, several held contrary views that restricting pharmacist prescribing to specific conditions or medicines may prevent a holistic medicines review.

"I think it is very hard to limit yourself to one section of the formulary... We don't want to get into a situation where we see the patients and we will say 'I can only prescribe this bit'."

Nursing Practice Leader 1

There was a wide-ranging discussion on the appropriate settings for implementing pharmacist prescribing. While it appeared that there was more support for implementation in the hospital sector, there was also potential for later implementation in other settings, including community pharmacy.

"At the time being, I believe that the hospitals should be the first people to implement it just to establish the fundamental things then after that we can expand it to PHCC and the community pharmacies."

Pharmacy Practice Leader 3

There was overwhelming agreement that pharmacist prescribers should undertake specific education and training prior to prescribing, irrespective of their prior qualifications.

"Train the pharmacists. It is not only training once... It has to be over a long period so that you ensure the sustainability of the skills and the knowledge they have obtained."

Academic Leader 2

Supervision was considered to be a key element of the programme to allow assessment of prescribing in practice and attainment of the required competence. 

really supportive that can kind of support the pharmacist through the process.”

\section{CFIR domain 3: Inner setting}

Implementation climate: Relative priority

213 (Individuals' shared perception of the importance of the implementation within the organisation)

214 Developing and implementing pharmacist prescribing was perceived to be a priority in keeping with the aims and ambitions of Qatar National Vision 2030 and the National Health Strategy.

"The triple aims that are set out in the National Health Strategy I think almost require us to think about pharmacist prescribing more because a major part of it is about safe care.”

Others noted that while pharmacist prescribing was important, other initiatives were more important to implement mainly due to the existing models of physician prescribing.

\section{Readiness for implementation: Available resources}

(The level of resources organisational dedicated for implementation and on-going operations including physical space and time)

Positive comments were received on resources which would be required for implementing pharmacist prescribing, especially in hospital setting.

"I can only talk about it from a hospital perspective but I have never worked in such well-resourced environment from a pharmacy perspective. So I think it may just be about reengineering and looking at different ways of practice."

Nursing Practice Leader 5

231 Some interviewees held contrary views, expressing views that additional resources would be required to 232 implement pharmacist prescribing.

"Right now, I think if I just look at HMC, there is not enough resources to just deliver care. So, I think, with this, it will be a resource intense effort."

Patient Safety Advocate 5

\section{CFIR domain 5: Process}

Planning developed in advance, and the quality of those schemes or methods) 

work that we have done, what are the issues for the various stakeholders.”

244 Aspects of governance were also considered key to successful implementation, by clearly describing the

245 prescribing framework and limits of prescribing.

246

"I would set up some sort of clear governance framework for it and so it is very clear at which point decisions are made and who is responsible and accountable for them."

Nursing Practice Leader 4

Many also discussed the requirement for business case planning, highlighting the weaknesses of the current system and the likely benefits to be gained from allowing pharmacists in Qatar to prescribe.

"You have to submit a good proposal showing the strengths and weaknesses, the SWOT [strengths, weaknesses, opportunities and threats] analysis and you should show them of course that this would be good."

Healthcare Policy Leader 2

\section{Engaging: Key stakeholders}

(Individuals from within the organisation that are directly impacted by the innovation, e.g., staff responsible for making referrals to a new program or using a new work process)

The need to consult and engage with wide-ranging groups of stakeholders was evident across all interviews.

"It is much easier to achieve change if you have everybody engaged and they will be more agreeable to a change because it is not being a change applied to them, it is applied with them.”

Patient Safety Advocate 3

Given that patients were at the centre of healthcare and the prescribing process, it was essential that their views were taken into account.

"My advice is to involve the patients as early as possible in the process of planning so even if they didn't accept it, you will know why."

Pharmacy Practice Leader 5

Policy makers across many health institutions in Qatar were also considered vital to the implementation process.

"I am quite positive that healthcare policy makers need to be on board. You need to get their buy-in to be able to promote it.”

Academic Leader 1

Support from pharmacy leaders was also considered crucial, with interviewees discussing the need for appropriate workload and balance.

"Say you have the staff already committed to do their own work, you need to give them protected time [to prescribe] and here you need the leaders to be involved."

Pharmacy Practice Leader 5 
272 Academics were highlighted as being key to the implementation of pharmacist prescribing particularly in

273 relation to education and training, and to ensuring appropriate standards of practice.

274 "I think for developing the competency or developing the guidelines maybe we will need the academic

275 people.” Pharmacy Practice Leader 3

276 On discussing engagement of the drug industry, many interviewees highlighted their concerns over their

277 involvement.

278 "You might want to have a representative as an observer, that is fine. But I don't think they can actually 279 have any input because they would be biased.”

Academic Leader 7

280 Categorisation of themes into facilitators and barriers to pharmacist prescribing implementation are given in

281 Table 4, illustrating a greater number of facilitators than barriers. Key facilitators were tailoring the model to

282 Qatar needs and providing additional training to pharmacists prior to allowing them to prescribe while the key

283 barriers reported include the current legislations in the state the potential initial resistance to this new role by

284 doctors and the public. 


\begin{tabular}{|c|c|c|c|}
\hline CFIR Domain & CFIR construct & Corresponding factors & $\begin{array}{l}\text { Classification } \\
\text { (Facilitator/Barrier) }\end{array}$ \\
\hline \multirow{16}{*}{$\begin{array}{l}\text { Innovation } \\
\text { characteristics }\end{array}$} & \multirow[t]{3}{*}{ Innovation source } & Awareness of non-medical prescribing and especially pharmacist prescribing practice globally & Facilitator \\
\hline & & Prescribing not currently within the scope of pharmacy practice in Qatar & Barrier \\
\hline & & Establishing the pharmacist-led anticoagulation clinic & Facilitator \\
\hline & Evidence strength and quality & Robust and rigorous evidence of effectiveness and safety reported globally & Facilitator \\
\hline & Relative advantage & $\begin{array}{l}\text { Potential to: } \\
\text {-Increase pharmacists' job satisfaction and confidence } \\
\text {-Reduce doctors' workload } \\
\text {-Provide timely and holistic care, increasing patients' experience and satisfaction } \\
\text {-Reduce cost of healthcare } \\
\text {-Improve image of the profession } \\
\text {-Expand role of pharmacy technicians }\end{array}$ & Facilitator \\
\hline & Adaptability & Potential to adapt models of pharmacist prescribing developed and implemented in other countries & Facilitator \\
\hline & Trialability & Potential to pilot on a small scale to determine effectiveness & Facilitator \\
\hline & \multirow[t]{5}{*}{ Complexity } & Lack of pharmacists' diagnostic skills & Barrier \\
\hline & & Need to ensure sufficient quality when prescribing & Facilitator/ Barrier \\
\hline & & Potential for conflict with physicians, most notably if an independently prescribing developed and implemented & Barrier \\
\hline & & Current legislative framework in Qatar & Barrier \\
\hline & & Impact on pharmacists' workload & Barrier \\
\hline & \multirow[t]{4}{*}{ Design quality and packaging } & Implementing collaborative prescribing before proceeding to a more autonomous model & Facilitator \\
\hline & & Need to prescribe in defined areas of clear need & Facilitator \\
\hline & & Preference to initially implement in secondary care prior to extending to other settings & Facilitator \\
\hline & & Requirement to provide additional education and supervised training & Facilitator \\
\hline \multirow[t]{2}{*}{ Outer setting } & $\begin{array}{l}\text { Needs and resources of those served by the } \\
\text { organisation }\end{array}$ & Public and healthcare professionals’ perceptions of pharmacists' education, training and practice & Barrier \\
\hline & Cosmopolitan & Ability to collaborate with other countries experienced in pharmacist prescribing implementation & Facilitator \\
\hline Inner setting & Networks and communication & Existing communication channels in secondary care & Facilitator \\
\hline
\end{tabular}




\begin{tabular}{|c|c|c|c|c|}
\hline & \multirow{4}{*}{ 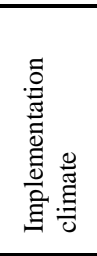 } & Tension for change & Shortage in the number of medical prescribers & Facilitator \\
\hline & & Compatibility & Quality of academic programme at the College of Pharmacy & Facilitator \\
\hline & & Relative priority & 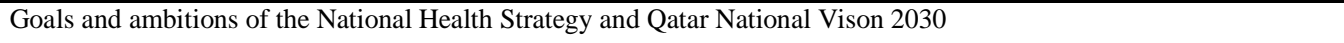 & Facilitator \\
\hline & & & Competing priorities & $\begin{array}{c}\text { Barrier } \\
\text { B }\end{array}$ \\
\hline & 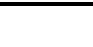 & $\begin{array}{ll}\text { Leadership engagement } \\
\end{array}$ & $\begin{array}{l}\text { Current discussions to extend pharmacists' clinical activities } \\
\end{array}$ & Facilitator \\
\hline & 尊 & Available resources & Availability of resources most notably in secondary care settings & Facilitator \\
\hline & 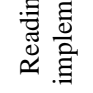 & & Need for additional resources to support implementation & 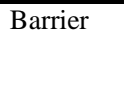 \\
\hline $\begin{array}{l}\text { Characteristics of } \\
\text { individuals }\end{array}$ & 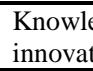 & $\begin{array}{l}\text { dge and beliefs about the } \\
\text { ion }\end{array}$ & Current knowledge base of practicing pharmacists & Facilitator \\
\hline & Self-eff & icacy & Pharmacists' lack of confidence to undertake a prescribing role & Barrier \\
\hline & Other $\mathrm{p}$ & ersonal attributes & $\begin{array}{l}\text { Pharmacy practice in Qatar considered as advanced as in Qatar as those countries which have implemented pharmacist } \\
\text { prescribing }\end{array}$ & Facilitator \\
\hline & & & Requirement for pharmacist prescribers to have experience in clinical area & Facilitator \\
\hline Process & 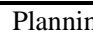 & & Engagement of other stakeholder groups to identify potential barriers & Facilitator \\
\hline & & & $\begin{array}{l}\text { Requirement to develop robust governance mechanisms (role definition, prescribing framework, model, etc.) } \\
\text { (a) }\end{array}$ & Facilitator \\
\hline & Engagi & g: Key stakeholders & $\begin{array}{l}\text { Early engagement of a wide range of stakeholders (pharmacy leaders, policy makers, patients, other providers, } \\
\text { academics etc.) }\end{array}$ & Facilitator \\
\hline & Reflect & ng and evaluating & Requirement to plan to monitor prescribing practice regularly & Facilitator \\
\hline
\end{tabular}




\section{Discussion}

288 Interviewees were generally aware of models of pharmacist prescribing in other countries and supported the

289 development and implementation in Qatar, with many potential benefits highlighted. Key facilitators highlighted

290 include adopting a more conservative model and providing additional training to pharmacists prior to

291 commencing prescribing. Main barriers were around the current legislative framework and potential initial

292 opposition by doctors and the public.

293 There are some similarities between the findings of this interview study and a recently published systematic

294 review.7 Focusing specifically on pre-implementation studies, several highlighted that major facilitators

295 identified pre-implementation included pharmacists' personal qualities (e.g. their clinical experience, education,

296 and training) and the perceived benefits of pharmacist prescribing (e.g. improved patient access to care and

297 better utilisation of pharmacists' skills). ${ }^{20-22}$ Studies in the systematic review also identified similar barriers in

298 pre-implementation studies including concerns over pharmacists' poor clinical skills in assessment and

299 diagnosing, which were key issues in relation to independent models of prescribing practice. ${ }^{20-25}$ These concerns

300 were reiterated in post-implementation studies and may indicate a misunderstanding of the UK independent

301 prescribing model which does not actually require the diagnosis to be made by the pharmacist independent

302 prescriber. $^{3}$

303 It is notable that these facilitators and barriers have been identified with groups of non-medical prescribers other

304 than pharmacists, as highlighted in a published umbrella review. ${ }^{4}$ Facilitators were non-prescribers' experience

305 as health professionals, the application of evidence-based guidelines and treatment protocols, peer support, and

306 encouragement from medical practitioners and patients. Barriers included the lack of clearly defined roles for

307 non-medical prescribers, no dedicated time allocated to prescribing activities, other competing tasks, lack of

308 confidence of some NMPs, and the lack of acceptance of the role by other health professionals and patients. ${ }^{4}$

309 Given that none of the studies included in these reviews had adopted CFIR or a similar framework, it is not

310 surprising that they did not comprehensively report the facilitators and barriers. Using CFIR in the interviews

311 identified additional facilitators and barriers, which should be considered as developments advance. These

312 include: tailoring the specific model of pharmacist prescribing to the needs of Qatar (innovation characteristics);

313 educating the public and other healthcare providers on pharmacists' education and training, and collaborating

314 with other countries that have implemented pharmacist prescribing (outer setting); aligning more to the goals

315 and ambitions of the health setting in Qatar, and considering more the readiness for implementation in Qatar

316 (inner setting); enhancing pharmacists' confidence to undertake a prescribing role (characteristics of

317 individuals); and developing robust governance standards and associated processes, involving a diverse group of

318 stakeholders in implementation, and evaluation of innovation (process).

319 These additional facilitators and barriers highlight the benefit of adopting a theoretical framework in research.

320 Identifying these factors pre-implementation can allow for a more tailored implementation, which will

321 overcome as many barriers as possible. This is likely to result in more successful and sustained implementation

322 with better outcomes for patients, professionals and the organisation. ${ }^{9-11}$ There is, therefore, merit in adopting

323 CFIR in all subsequent stages of development and implementation of pharmacist prescribing in Qatar, as 
324 discussed earlier. Such an approach may also be relevant for any other country considering implementation of

325 pharmacist prescribing.

326 There are many strengths to this study. First, to the best of our knowledge, this is the first and only study on

327 pharmacist prescribing which has used a theoretical framework of implementation throughout the research

328 processes hence represents an original contribution to knowledge. Moreover, a qualitative methodology allowed

329 the generation of in-depth, rich data allowing detailed description and understanding of perspectives. ${ }^{26}$ Key

330 stakeholders in positions of power and influence were recruited which would later enable actual implementation

331 of pharmacist prescribing. Data saturation was observed across and within all stakeholder groups, hence, the

332 rigour of the findings and likelihood of implementation increased. The main limitation of this research is that the

333 data were generated in Qatar hence the findings may lack transferability to other countries in the Middle East

334 and beyond. However, attention has been paid to describing the research setting, methods, and interviewees to

335 allow readers to consider likely transferability to their own settings and individuals.

336 Future research needs to focus on determining the most suitable framework and training needs for pharmacist

337 prescribing in Qatar. A consensus-based approach, such as the Delphi technique, with a similar group of

338 stakeholders used in this study could be an appropriate approach since it is particularly useful in developing

339 policies, supporting governance, and stimulating debate around areas where there is uncertainty or incomplete

340 evidence. ${ }^{27-30}$

341

\section{Conclusion}

343 This qualitative study of key stakeholders in Qatar has demonstrated the potential for pharmacist prescribing to

344 be developed and implemented in Qatar. Using CFIR pre-implementation has identified key facilitators and

345 barriers which can be considered as part of action planning, most notably defining models of prescribing

346 suitable for Qatar, within a governance framework of education, training and accreditation.

348 Declarations of interest: None.

349 Funding: This research did not receive any specific grant from funding agencies in the public, commercial, or 350 not-for-profit sectors. 
352 1. Stewart D, Maclure K, George J. Educating non-medical prescribers. British Journal of Clinical

353 Pharmacology. 2012; (74): 662-667.

354 2. Cope L, Abuzour A, Tully M. Nonmedical prescribing: where are we now? Therapeutic Advances in Drug 355 Safety. 2016; 7(4): 165-172.

356 3. UK Department of Health. Improving patient's access to medicines: A guide to implementing nurse and pharmacist independent prescribing within the NHS in England. http://webarchive.nationalarchives.gov.uk/+/www.dh.gov.uk/en/PublicationsandStatistics/Publications/Publ icationsPolicyandGuidance/DH_4133743; 2006 Accessed 13/05/2016.

4. Stewart D, Jebara T, Cunningham S, Awaisu A, Pallivalapila A, MacLure K. Future perspectives on nonmedical prescribing. Therapeutic Advances in Drug Safety. 2017; 8(6): 183-197.

5. Weeks G, George J, Maclure K, Stewart D. Non-medical prescribing versus medical prescribing for acute and chronic disease management in primary and secondary care. Cochrane Database of Systematic Reviews. 2016; 11: CD011227.

6. Poh EW, McArthur A, Stephenson M, Roughead EE. Effects of pharmacist prescribing on patient outcomes in the hospital setting: a systematic review. JBI Database of Systematic Reviews and Implementation Reports. 2018; 16(9): 1823-1873.

7. Jebara T, Cunningham S, MacLure K, Awaisu A, Pallivalapila A, Stewart D. Stakeholders' views and experiences of pharmacist prescribing: a systematic review. British Journal of Clinical Pharmacology. 2018; 84: 1883-1905.

8. Craig P, Dieppe P, Macintyre S, Michie S, Nazareth I, Petticrew M. Developing and evaluating complex interventions: new guidance. https://www.mrc.ac.uk/documents/pdf/complex-interventions-guidance/; 2008 Accessed 18/07/2016.

9. Nilsen P. Making sense of implementation theories, models and frameworks. Implementation Science. 2015; 10: 53.

10. Damschroder LJ, Aron DC, Keith RE, Kirsh SR, Alexander JA, Lowery JC. Fostering implementation of health services research findings into practice: a consolidated framework for advancing implementation science. Implementation Science. 2009; 4: 50.

11. Consolidated Framework for Implementation Research. Welcome to the CFIR Technical Assistance Website. http://cfirguide.org/; 2016 Accessed 07/09/2016.

12. World Bank. Qatar. http://data.worldbank.org/country/qatar; 2016 Accessed 21/03/2016.

13. Qatar General Secretariat for Development Planning and Statistics. Qatar National Vision 2030. http://www.gsdp.gov.qa/portal/page/portal/gsdp_en/qatar_national_vision; 2008 Accessed 10/01/2016.

14. Qatar Supreme Council of Health. National Health Strategy 2011-2016. http://www.qu.edu.qa/pharmacy/components/upcoming_events_material/Qatar_National_Health_Strategy.p df; 2013 Accessed 10/01/2016.

15. Qatar National Research Fund. Qatar National Research Strategy (QNRS). http://www.qnrf.org/enus/About-Us/QNRS; 2014 Accessed 18/01/2016.

389 16. Qatar Ministry of Public Health. National Health Strategy 2018-2022.

390 https://www.moph.gov.qa/HSF/Pages/NHS-18-22.aspx; 2018 Accessed 10/06/2018. 
17. Francis JJ, Johnston M, Robertson C, Glidewell L, Entwistle V, Eccles MP, Grimshaw JM. What is an adequate sample size? Operationalising data saturation for theory-based interview studies. Psychology \& Health. 2010; 25(10): 1229-1245.

18. Hannes K. Critical appraisal of qualitative research. In: Noyes J, Booth A, Hannes K, Harden A, Harris J, Lewin S, Lockwood C, eds. Supplementary Guidance for Inclusion of Qualitative Research in Cochrane Systematic Reviews of Interventions, Version 1. NK: Cochrane Collaboration Qualitative Methods Group. http://cqrmg.cochrane.org/supplemental-handbook-guidance; 2011 Accessed 15/08/2016.

19. Howitt D. Introduction to qualitative research method in psychology. $3^{\text {rd }} \mathrm{ed}$. Malaysia: Pearson Education Limited; 2016.

400

20. Hanes C, Bajorek B. Pharmacist prescribing: Views of Australian hospital pharmacists. Journal of Pharmacy Practice and Research (Australia). 2005; 35: 178-180.

21. Auta A, Strickland-Hodge B, Maz J. Stakeholders' views on granting prescribing authority to pharmacists in Nigeria: a qualitative study. International Journal of Clinical Pharmacy. 2016; 38(4): 960-967.

22. Auta A, Strickland-Hodge B, Maz J, David S. Pharmacist prescribing: a cross-sectional survey of the views of pharmacists in Nigeria. International Journal of Pharmacy Practice. 2018; 26(2): 111-119.

406

23. Nguyen N, Bajorek B. Pharmacist prescribing in warfarin therapy: Exploring clinical utility in the hospital setting. Journal of Pharmacy Practice and Research (Australia). 2008; 38: 35-39.

408

24. Hoti K, Sunderland B, Hughes J, Parsons R. An evaluation of Australian pharmacist's attitudes on expanding their prescribing role. Pharmacy World \& Science: PWS. 2010; 32(5): 610-621.

25. Erhun W, Osigbesan T, Awogbemi K. Study of pharmacists' and physicians’ views on pharmacist prescribing in Nigeria. West African Journal of Pharmacy. 2013; 24(2): 76-82.

26. Jensen E.A, Laurie C. Doing real research: A practical guide to social research. $1^{\text {st }}$ ed. London: Sage Publications; 2016.

27. Jones J, Hunter D. Qualitative research: Consensus methods for medical and health services research. British Medical Journal. 1995; 311(7001): 376-80.

28. Campbell S, Cantrill J. Consensus methods in prescribing research. Journal of Clinical Pharmacy and 417 Therapeutics. 2001; 26: 5-14.

418 29. Keeney S, Hasson F, McKenna H. The Delphi technique in nursing and health research. 1st ed. Chichester: Wiley-Blackwell Publishing; 2011.

420 30. Nair R, Aggarwal R, Khanna D. Methods of formal consensus in classification/diagnostic criteria and 421 guideline development. Seminars in Arthritis and Rheumatism. 2011; 41(2): 95-105. 